\title{
Do markets care enough about deficit to raise future cost of capital? Non-linear deficit- interest rate relationship in the U.S. economy
}

\author{
ATANU RAKSHIT ${ }^{1}$ \\ Graduate School of Business, Nazarbayev University, Kabanbay Batyr Ave 53, Astana 010000, \\ Kazakhstan \\ (E-mail: atanu.rakshit@nu.edu.kz)
}

\begin{abstract}
$\underline{\text { Abstract }}$
This paper finds strong evidence of non-linear impact of long-horizon expected government deficits, measured by $\mathrm{CBO}$ projections, on expected future long-term interest rates for the US economy. The impact of a shock to expectations ("news shock") in a regime where the expected deficit/GDP ratio is above $1.8 \%$ (the estimated threshold value) increases future nominal interest rates by 29-30 basis point, and future real rates by 12-18 basis points. When expected deficit/GDP ratio is below $1.8 \%$, a surprise increase in expectations of deficit has no statistically significant impact on future interest rates.
\end{abstract}

JEL classifications: C22, C32, E43, E62

Keywords: deficits; interest rates; threshold.

I gratefully acknowledge helpful comments from colleagues at Virginia Tech., in particular, Richard Ashley and Kwok Ping Tsang as well as seminar participants at the Fuqua School of Business. I am thankful to Vipul Bhatt from James Madison University for his assistance, and Thomas Laubach from the Board of Governors of Federal Reserve System for kindly providing me with part of the data for this paper. 


\section{Introduction}

Economic theory posits that the effect of deficit on long term interest rates is an important channel through which deficit affect the real sector of the economy. For instance, fluctuations in long term rates may impact interest-sensitive components of private spending such as housing and business fixed investment. Hence, understanding how deficits impact long term rates is of policy interest.

In extant literature, the relationship between deficit and long term interest rates has been extensively studied, but with ambiguous results. One major reason behind this ambiguity is due to the fact that deficit-interest relationship is confounded by the phenomenon that different policy measures, both monetary and fiscal, may impact deficit and interest rates contemporaneously. For example, if long-term interest rates fall due to monetary easing during recessions, while automatic stabilizers raise the deficit, deficits and interest rates may be negatively correlated even if the partial effect of deficits on interest rates - controlling for all other influences- is positive. Recent literature addresses this issue by accounting for the role of expectations about debt and deficit ${ }^{2}$ while estimating the aforementioned relationship.

The dynamics of the relationship between deficit and long term interest rates is thus essentially an empirical question, which is what this paper tries to address. In this paper, I argue that it is also important to account for the possible nonlinearities in the relationship between long term interest rates and the level of expected deficit.

In this paper I depart from the Laubach (2009) single-equation framework of deficit-interest rate relationship and incorporate threshold effects in expected deficits. Specifically, I estimate a threshold model where the level of threshold is unknown and is estimated along with other Gale and Orszag (2002, 2003), Laubach (2009). ${ }^{2}$ 
parameters of the linear regression model. Using the estimated threshold level for expected deficit from this model, I specify and estimate a threshold VAR model to estimate response of future long term rates to structural shocks to deficit expectations, and allow this response to differ across the threshold levels.

There are several findings of interest. First, similar to Laubach (2009), I find that expected deficit increases the future long term rate $^{3}$. However, I also find that there is a significant threshold effect in this relationship. Specifically, the relationship between expected deficit and interest rate is only significant during the regime of high expected deficit. My estimated threshold level for the projected-deficit GDP ratio is 1.8 for the US economy. I find that for values of projected-deficit GDP ratio higher than this threshold level, a percentage point increase in the projected deficit GDP ratio increases future long term nominal interest rate by 30 basis points.

Using the estimated threshold level from the single equation framework, I also run a Threshold VAR with other economic control variables. I find that a one standard deviation shock to projected deficits increases the real future long term interest rate by 16 basis points in a 'high' deficit regime for almost a period of 12 months before reverting to the mean. In contrast, in the 'low' deficit regime the impact is negligible. This means that the impact of an innovation to projected deficit acts not only through the expected inflation channel, but directly on the economy's real rate of return.

One way to interpret the results of my Threshold VAR is to consider an innovation to the projected deficit variable as a revision of market's expectation of future deficit. In a regime 
where economic agents already expect deficit to be high in the future, any revision of such projections will likely have large and significant impact on future interest rates (agents expect future interest rates to be high).This will not be the case when economic agents expect future deficit to be below a certain threshold value

\section{Related Literature}

Although several different surveys over the past twenty years have evaluated the literature on the relationship between federal government debt/deficit and interest rates ${ }^{4}$, the empirical evidence on the relationship between deficit and interest rates is at best mixed. A survey of the literature by Seater (1993) finds support for the Ricardian equivalence hypothesis, which implies that federal government debt has no effect on interest rates. Barro (1989) takes a similar position as Seater (1993), concluding: "Overall, the empirical results on interest rates support the Ricardian view. Given these findings, it is remarkable that most macroeconomists remain confident that budget deficits raise interest rates." Bernheim (1989) on the other hand finds little evidence for the neutrality of government debt. Elmendorf and Mankiw (1999) summarize this literature by stating that: 'Our view is that this literature, like the literature regarding the effect of fiscal policy on consumption, is ultimately not very informative. Examined carefully, the results are simply too hard to swallow'.

A more recent survey paper by Gale and Orszag (2004) emphasizes that empirical study that (properly) incorporates deficit and debt expectations in addition to current deficit tends to find

(Bernheim (1987, 1989); Barro (1989); Seater (1993); Elmendorf and Mankiw (1999); and Gale and Orszag (2002, 2003). ${ }^{4}$ 
economically and statistically significant connections between anticipated deficits and current long-term interest rates. A recent paper by Laubach (2009) explicitly focuses on long horizon forecasts of fiscal variables and interest rates. Laubach incorporates CBO deficit projections in his analysis as a proxy for expectations, and looks at the impact of the projections on future short and long interest rates, and finds significant positive relationship among these two variables.

The literature on non-linearity in fiscal policy (mainly dealing with correctly estimating the size of government spending or tax multiplier during a recessionary regime and expansionary regime) is relatively new, with the most current and influential paper being Auerbach and Gorodnichenko (2012). In their paper, the authors incorporate regime in GDP growth in keeping with their research question, and endogenously determine regime switches and estimate regime dependent multipliers in a VAR specification.

Another paper which uses a more conventional Threshold VAR to incorporate non-linearity in fiscal policy is Candelon and Lieb (2011). Although structural VAR specifications have been the workhorse for finding out the impact of fiscal variables on monetary policy and vice versa ${ }^{5}$, the existence or estimation of non-linearity in their relationship is rare in the literature. One important reason for that is the small size of available historical fiscal data and the potential empirical issues that researchers might have to encounter with the large number of parameters generated in any non-linear model.

The specific form of non-linearity that I am looking at is novel in two ways. Firstly, nonlinearity in the impact of expected deficit on interest rates has not been addressed in the literature to my knowledge. Secondly, although it is fairly straightforward to do a Threshold VAR where non-linearity in one of the variables can be endogenously determined, thereby generating regime dependent impulse responses following Tsay (1998), given the small sample size of government Mountford and Uhlig (2000), Perotti (2002), Engen and Hubbard (2004). ${ }^{5}$ 
deficit data, it is near to impossible to get any statistically meaningful results in a non-linear VAR with its numerous parameters. The empirical strategy of this study is to test for nonlinearity in expected deficit and estimate its threshold value in a simpler single equation framework using Hansen (2000) asymptotic method, which addresses the issue of the small sample size. I then use this estimated threshold value to create a dummy which I interact with the projected deficit variable in the VAR to corroborate my results from the single equation framework.

\section{Empirical Specifications}

In the absence of nominal rigidities in the economy, the real interest rate is equal to the "natural" rate of interest $r_{t}^{*}$ and only deviates from it in the presence of nominal rigidities, where the short term rate takes the form $r_{t}=i_{t}-E_{t} \pi_{t+1}{ }^{6}$ Laubach (2009) is motivated by this theory to specify regressions for the real rate of the general form $r_{t}^{*}=\alpha+\beta f_{t}+u_{t}$ where $f_{t}$ is the given measure of fiscal policy, and $u_{t}$ denotes other factors affecting the natural rate (specifically, growth rate of per capita consumption, the inter-temporal elasticity of substitution, and household's rate of time preference). The observed real short-term interest rate can thus be written as $r_{t}=\alpha+\beta f_{t}+u_{t}+\left(r_{t}-r_{t}^{*}\right)$ where the real-rate gap $\left(r_{t}-r_{t}^{*}\right)$ is unobserved, and is subsumed in the residual of a regression of the current interest rate on fiscal factors. But this gives rise to a potential endogeneity problem in a setting where the real rate gap varies over time due to, for example, countercyclical monetary policy, and while at the same time automatic stabilizers induce cyclical variation in the fiscal variable $f_{t}$. However, since nominal rigidities are only temporary, for sufficiently long horizons $k$ the real rate gap should vanish in

Woodford (2003) gives detailed exposition on this. ${ }^{6}$ 
expectation, that is $E_{t-k}\left(r_{t}-r_{t}^{*}\right)=0$. One way to address this endogeneity problem is to focus on expectations of interest rates and fiscal variables sufficiently far into the future. My test for the existence of threshold and its estimation is thus run on a variant of Laubach's regression, which takes the form:

$$
E_{t}\left(i_{t+k}\right)=\beta_{0}+\beta_{1} E_{t}\left(\pi_{t+k}\right)+\beta_{2} E_{t}\left(f_{t+k}\right)+\beta_{3} E_{t}\left(u_{t+k}\right)+\varepsilon_{t}
$$

where the dependent variable is the long-term nominal interest rate expected to prevail $k$ periods ahead, the coefficient $\beta_{1}$ on expected inflation can be different from 1 , and $u_{t}$ denotes additional regressors. The main interest is in the magnitude and statistical significance of $\beta_{2}$ and especially whether it takes significantly different values in different regimes of the fiscal variable (in the case where regimes are present).

In the following section (Section 4) I intend to specify one such stylized fact about the link between future long term rates and expected deficit/debt, mainly that there is an unambiguous threshold effect of expected deficit on future long term interest rate. In that section I also estimate the threshold and its confidence interval in a single equation regression framework of the type (1), and test whether there is a threshold effect of expected deficit/ debt on future long rates. In Section 5, I estimate a Threshold VAR using current and projected fiscal variables and future interest rates. My goal is to characterize the empirical relationship between future longterm interest rates, expected debt and deficit, expected inflation and expected GDP growth rates, while placing as few theoretical restrictions on the system dynamics as possible. I summarize and conclude in Section 6. Before I look into the nature and results of threshold tests and the Threshold VAR, I describe the data in the next sub-section. 


\section{data and their properties}

Following related literature ${ }^{7}$, I use Congressional Budget Office (CBO) published projections of debt, deficit $\left(E_{T} d_{t+k}\right)$ and GDP growth rates $\left(E_{T} y_{t+k}\right)$ as the fiscal variables, with the first two expressed as percentages of projected GNP or GDP, as a proxy for expectations of future fiscal policy. The forecast horizon is 5 years in the future, which is the longest horizon for which a reasonably long time series of projections is available. Consistent with the use of 5-year-ahead projections of fiscal variables by the $\mathrm{CBO}$, the analysis focuses on forward rates 5 years ahead embedded in the term structure of interest rates. In other words, I use 5 year ahead 5-year forward rate (and 5 year ahead 10-year forward rate) $E_{T} i_{t+k}$, calculated from zero coupon yield curve dataset of Gurkanayak, Sack and Wright (2006), details of which are in Appendix A. A significant component of any movement in future long term rates would be that of inflation expectations (of matching maturity), and I use a measure of long horizon inflation expectations $E_{T} \pi_{t+k}$ composed of a spliced series from both survey data and models of professional forecasters over the time period of my sample (details in Appendix A). The series of interest rates and inflation expectations are shown in Figure 1. The unified budget deficit, debt and GDP projections used are at semi-annual frequency from 1985, rather than the annual frequency which goes back till 1976, since that way I get more observations in my sample. Also, I wanted to avoid the significantly higher volatility of projected deficit and expected inflation pre-1985 to influence my results.

Laubach (2009), Wachtel and Young (1987), Cohen and Garnier (1991), Elmendorf (1993). For a brief review of these papers, see Laubach (2009). None of these papers deal with non-linear effects of debt on interest rates. I am grateful to Thomas Laubach for making his updated dataset on projected deficit and GDP growth rates available to me. For details regarding construction of the data and their stationary properties, see Laubach (2009). ${ }^{7}$ 
In Figure 2, I show the CBO data on projected deficit, projected debt and projected GDP growth. For details on the forecast errors of the projections data and stationarity properties, refer to Laubach (2009) who gives a detailed exposition on the issue. The projections are shown for the fiscal year in which they are made. Figures 11 and 12 provide some descriptive statistics of projected deficit/GDP ratio and projected GDP growth rates.

\section{Threshold Estimation}

The test for non-linear effects of expected debt on future interest rates based on an asymptotic distribution theory of threshold estimates in a regression developed by Hansen (2000). In a routine analysis of sub-sample stability of parameters of a regression of the form $y_{t}=\beta^{\prime} x_{t}+e_{t}$, either a threshold value to split the sample is specified, or in the case where such specification is lacking, some method is employed in its selection. Such practices can be formally treated as a special case of the threshold regression model. These take the form:

$$
\begin{array}{ll}
y_{t}=\theta_{1}^{\prime} x_{t}+e_{t}, & q_{t} \leq \gamma \\
y_{t}=\theta_{2}^{\prime} x_{t}+e_{t}, & q_{t}>\gamma
\end{array}
$$

where $q_{t}$ may be called the threshold variable, and is used to split the sample into two groups, which may be called "classes" or "regimes" depending on the context.

Hansen (2000) develops an asymptotic approximation to the distribution of the least squares estimate $\hat{\gamma}$ of the threshold parameter $\gamma$. The specification that I use to test for a threshold, as well as to search a threshold from information contained within the regression framework, is: 


$$
i_{t}=\beta^{\prime} X_{t}+e_{t}
$$

where $i_{t}$ is the 5 -year-ahead 5 year and 10 year interest rates (more easily visualized as $E_{T} i_{t+k}$ where $k=5$ in my case) and $X_{t}$ is a $t \times l,(l=4)$ vector of explanatory variables $\left[d_{t}, y_{t}, \pi_{t}, e p_{t}\right]$. Although all the explanatory variables are denoted as current period time series for ease of notation, they should be more appropriately interpreted as expectation terms in the same vein as $i_{t}$ i.e. $d_{t}$ denotes $E_{T} d_{t+k}, y_{t}$ denotes $E_{T} y_{t+k}, \pi_{t}$ denotes $E_{T} \pi_{t+k}$. As a proxy for expected debt, the series of CBO semi-annual 5- year ahead deficit projections constitute $d_{t}$, the series of CBO projections of GDP growth rates is what constitutes $y_{t}$, and the series of long term inflation expectations are captured by the variable $\pi_{t}$. The imposition of the variable of $e p_{t}$ in the regression (and in the VAR) is due to a different restriction. It denotes a time varying measure of relative risk aversion for the economy as a whole, defined as the dividend component of national income divided by the market value of corporate equities held (directly and indirectly) by households as reported in the Federal Reserve's Flow of Funds data (details in Appendix A).

To write Eq. 4 as a threshold regression of the type in Eq. 2 and Eq. 3, while still keeping the single equation framework, I define the dummy variable $d_{t}(\gamma)=\left\{q_{t} \leq \gamma\right\}$ where $\{$.$\} is the$ indicator function and $q$ can be any element of the vector X (in my case, its projected deficit $d_{t}$ ). Setting $X_{t}(\gamma)=X_{t} d_{t}(\gamma)$, I now have a threshold variant of Eq. 4 .

$$
i_{t}=\beta_{1}^{\prime} X_{t}+\beta_{2}^{\prime} X_{t}(\gamma)+e_{t}
$$


where $\beta_{1}^{\prime}$ is the equivalent of $\theta_{2}^{\prime}$ in Eqs. 1-2. The regression parameters are then $\left(\beta_{1}^{\prime}, \beta_{2}^{\prime}, \gamma\right)$ and the natural estimator is the Least Squares (LS). Hansen's asymptotic method then not only tests for the presence of threshold, but also estimates the confidence interval around the "true" threshold. Figure 3 and Figure 4 shows the F test for linearity in projected deficit in the regression framework specified above, and it shows that the null of no-threshold is rejected at $5 \%$ for 5 -year ahead 10 year interest rate and at $10 \%$ for 5 -year-ahead 5 year interest rate.

\section{results of threshold estimation}

A common method to form confidence intervals for parameters is through the inversion of Wald or the t-statistics. Given that the sampling distribution of threshold parameter depends on unknown parameters since the threshold itself is not identified in some parameter space, the Wald statistic will have very poor finite sample behavior ${ }^{8}$. Hansen (2000) showed that under such circumstances, precise confidence interval can indeed be constructed using the likelihood ratio statistic $L R_{n}(\gamma)$ where $\gamma$ is the threshold parameter.

Figure 5 and Figure 6 displays the graph of the normalized (scaled to account for heteroskedasticity $\left.{ }^{9}\right)$ likelihood ratio sequence $L R_{n}^{*}(\gamma)$ as a function of the threshold in projected deficit. The LS estimate of $\gamma$ is the value that minimizes these graphs, which occurs at $\hat{\gamma}=1.800$ for both the cases. Table 1 elaborates the result of the threshold estimation and confidence interval construction. The $95 \%$ critical value is also plotted (the dotted line) so one can read off the asymptotic $95 \%$ confidence set from the graph where the $L R_{n}^{*}(\gamma)$ crosses the dotted line. These results show that there is reasonable evidence of 2 regime specification.

See Dufour (1997). ${ }^{8}$

See Hansen (2000) for details. ${ }^{9}$ 
The impact of projected deficit on 5-year-ahead 5 year and 5-year-ahead 10 year interest rates, based on the regression in Equation 4 is shown in Table 2. In the full sample, a percentage point increase in projected deficit GDP ratio increases 5 year-ahead 5 year interest rates by 16 basis points. This is close to what Laubach (2009) derives, which is typically a 22 basis point increase for a percentage point increase in projected deficit. Similarly, in the full sample, a percentage point increase in projected deficit GDP ratio increases 5-year-ahead 10 year interest rates by 18 basis points.

Once I fix $\gamma$ at the LS estimate of 1.8 and split the sample in two based on this value of projected deficit, my sample approximately splits in half. Running the same regression for the two subsamples divided on the basis of the threshold, I find some very interesting results. Table 3.1 and 3.2 present the results of the regression (Equation 5). When projected deficit is below the threshold value of $\gamma=1.8$ (I call this Regime 1), the impact of projected deficit becomes insignificant in both cases. In Regime 2, when projected deficit takes value higher than the threshold, a percentage point increase in projected deficit significantly raises 5 -year-ahead 5 year interest rates by 30 basis points and 5 -year-ahead 10 year interest rates by 29 basis points. The magnitude of the effect is thus more than double of what I get when I use the full sample (i.e. when I use a model in which I do not specify the presence of a threshold).

In other words, in a regime of high expected deficit, the market's reaction to increased future deficit will markedly differ from when expected deficit is below a certain threshold. The economy's expectation of future long term interest rates under the former scenario (being greater in magnitude and statistically significant) is thus different than under the later. This important distinction contains a new and important piece of information for the policy process. It is that the impact of expected deficit on future interest rates, and thus national savings and GDP, might be 
small or ambiguous during a period of low and low expected deficit (where outlay plans plus net interest payments does not exceed planned tax revenues by a certain threshold amount), but is clear and significantly large in a period of high or high expected deficit (where government outlay including net interest payments exceed tax revenue over a threshold value). To investigate the nature of the impact on future interest rates of expected deficit, I now carry out a Threshold VAR, so that that I can introduce richer dynamics among the variables. The specification of the Threshold VAR and impulse responses are discussed in the next section.

\section{Threshold VAR}

Threshold VARs are piecewise linear models with different autoregressive matrices in each regime. The regimes are determined by a transition variable, which is either one of the endogenous variables or an exogenous variable, as in Hansen $(1996,1997)$ and Tsay (1998). In general it is possible to obtain more than one critical threshold value and therefore more than two regimes, but since Hansen (2000) test generates one threshold value for my data on deficit, I will work with only two regimes.

Let a set of $k$ stationary endogenous variables with $x_{t}=\left(x_{1 t}, \ldots, x_{k t}\right)^{\prime}$ and $T$ observations describe a VAR of finite order $p$

$$
x_{t}=\Gamma_{0}+\Gamma_{1} x_{t-1}+\cdots+\Gamma_{p} x_{t-p}+u_{t}
$$

where $\Gamma_{0}$ is a $k$-dimensional vector containing deterministic terms such as a constant, a linear time trend or dummy variables. $\Gamma_{i}$ with $i=1, \ldots, p$ are squared coefficient matrices of order 
$k$, and $u_{t}$ is a sequence of serially uncorrelated random vectors with mean zero and covariance matrix $\operatorname{Cov}\left(u_{t}\right)=\Sigma u$. I can rewrite equation (6) in the compact form

$$
x_{t}=\Gamma X_{t}+u_{t}
$$

With $\Gamma=\left(\Gamma_{0}, \Gamma_{1}, \ldots, \Gamma_{p}\right)$ and $X_{t}=\left(1, x_{t-1}, \ldots, x_{t-p}\right)^{\prime}$. Following this notation, a threshold VAR is represented by

$$
x_{t}=\Gamma_{1} X_{t}+\Gamma_{2} X_{t} I\left[z_{t-d} \geq z^{*}\right]+u_{t}
$$

$z_{t-d}$ is the threshold variable determining the prevailing regime of the system, with a possible lag $d . I[\cdot]$ is an indicator function that equals 1 if the threshold variable $z_{t-d}$ is above the threshold value $z^{*}$ and 0 otherwise. The coefficient matrices $\Gamma_{1}$ and $\Gamma_{2}$, as well as the contemporaneous error matrix $u_{t}$ are allowed to vary across regimes. Although conventional Threshold VARs, following Tsay's (1998) influential paper on the topic, treat the delay lag $d$ and critical threshold value $z^{*}$ as unknown parameters to be estimated, I treat them differently. Given my small sample size and the multitude of parameters that a VAR would estimate (more so in a Threshold VAR), I treat my threshold value as known. Specifically, I use the threshold value of deficit that I estimated using the Hansen (2000) methodology. Not only is Hansen's method more robust to small sample size, the asymptotic theory developed by Hansen aids in the construction of confidence interval around the estimated threshold value, which Tsay's test does not allow for. The choice of $d$ in Threshold VAR usually relies on economic reasoning. I 
estimate the VAR using semi-annual data with a known value of $z^{*}=\gamma=1.8$ and restrict $d$ to be zero i.e. Eq. 8 can be re written as

$$
x_{t}=\Gamma_{1} X_{t}+\Gamma_{2} X_{t} I\left[z_{t-d} \geq \gamma\right]+u_{t}
$$

where $\gamma=1.8$. Conventional non-linear specification of VAR often includes an additional variable to distinguish between the regime of interest (example: some transformation of output gap to indicate "good" and "bad" times in fiscal VAR literature ${ }^{10}$ ). An important distinction between my specifications from those used in the literature is that I do not introduce such additional variable, instead restricting one of the endogenous variable of the VAR (projected deficit) to be the threshold variable. Although introducing a measure of output gap as a threshold variable would be fairly straightforward, the nature of the question that I am asking makes such a measure problematic. Government budget deficit, both current and projected, is counter-cyclical and would generally have relatively higher values during recessions. If I use output gap as a threshold variable as is the practice in non-linear fiscal VAR literature, I would be creating an endogeneity problem. Also, when I ran the asymptotic test in the single equation framework of the type in Eq.5, I found no non-linear effect of expected output gap on future long term interest rates.

In my version of threshold VAR, $x_{t}=\left[R r_{t}, d_{t}, y_{t}\right]$, where all the variables are those that were used in the single equation regression, except $R r_{t}$, which is the real 5 year ahead 5 year interest rate (which is obtained by subtracting the expected long term inflation from the nominal

Auerbach and Gorodnichenko 2012a, 2012b. ${ }^{10}$ 
forward rates i.e. $\left.R r_{t}=i_{t}-\pi_{t}\right)$. Again, the expectational nature of the variables is implicit in the notation, as explained in the Section 3.

I couch my main results in the form of impulse-response functions (IRFs henceforth), estimated in the usual way. I compute 90\% bootstrapped confidence intervals based on 1000 replications, and focus my discussion on significant responses. I report the resulting structural impulse-response functions in Figs. 7-10.

\section{results of threshold VAR}

Using an estimated threshold value of 1.8 for the projected deficit-GDP ratio, the Threshold VAR corroborates my findings from the single equation framework and provides a new insight. The impulse responses show that a Cholesky one standard deviation shock to projected deficit increases the real future long term interest rate by 12 basis points in a 'high' deficit regime (projected deficit-GDP ratio greater than 1.8). This increase is persistent for almost a year and half before reverting back to its mean. In the "low" deficit regime, the impact is a small 3 basis point drop in the real rate, which reverts back to its pre-innovation level in 6 months' time.

The impact of an innovation to projected deficit on real rates indicates that the deficit-interest dynamics acts not only through the expected inflation channel, but directly on the economy's real rate of return. One way to interpret the results of my Threshold VAR is to consider an innovation to the projected deficit variable as a revision of market's expectation of future deficit that is independent of the CBO's forecast. The smyce of the shock can also be thought of as some information private to $\mathrm{CBO}$ which becomes public. In a regime where economic agents already expect deficit to be high in the future, any revision of such projections will likely have large and significant impact on future real interest rates (agents expect future interest rates to be

high). This will not be the case when economic agents expect future deficit to be below a certain 
threshold value. The VAR structure, while imposing the minimum if theoretical restrictions on the dynamics, controls for the fact that some part of projected deficit will have to incorporate future interest payments and GDP growth rates. It also enables us to look at the impact of an innovation to expected deficit on future real rates, which a single equation set up does not.

\section{robustness checks}

To see how robust my results are to the nature of data as well as specifications of the single equation regression and Threshold VAR, I carry out the entire exercise using an alternative measure of equity premium and using additional data on government spending projections and projections error in my VAR. The results of such exercises are qualitatively and quantitatively similar to what I present in my main results, both in the single equation Threshold estimation model and in the VAR. I also test the sensitivity of my result in the single equation to the threshold value of deficit/GDP that is estimated. Specifically, I carry out the threshold regression and the VAR using values of threshold around the neighborhood of 1.8 , and find my result to be robust to such specification. The VAR impulse responses are also robust to different ordering of the variables in the Cholesky ordering as long as I order slower moving variables last ${ }^{11}$.

\section{Conclusion}

In this paper I document empirical evidence in favor of significant non-linearity in the deficitinterest rate relationship in the US economy. When I test for a threshold effect in the impact of fiscal deficit expectations on future long term interest rates, I find presence of significant threshold that can be used to explore the deficit-interest rate relationship in two regimes. In the

Results are available on request ${ }^{11}$ 
"low-regime", when the economy's expectation of future fiscal deficit is low, deficits will have a negligible impact on long term interest rates. However, this effect is positive and significant (both economically and statistically) in the "high-regime", when the economy expects that future deficit will be higher than a certain threshold (a deficit-GDP ratio of 1.8). The size of the impact is 30 basis points for one percentage point increase in expected deficit/GDP ratio. I utilize the estimated threshold value of deficit and run a threshold VAR to explore the dynamics of the impact of a structural shock to deficit expectations on long term rates. A structural shock to deficit expectations can be interpreted as a revision to Congressional Budget Office (hence the market's) forecast of future revenue and spending scenario (the timing of taxes or the path of government spending). The result of this paper suggests that any such revision will have significant impact on future interest rates (hence future investment, consumption and savings) in a scenario where expectations of deficit are already high.

This evidence is not only interesting to policymakers in designing debt stabilization strategies but it can also help reconcile conflicting predictions about the effects of deficit on interest rates across different types of macroeconomic models. A novel implication of my result is that it might be worthwhile for policymakers to incorporate management of deficit-expectations in their policymaking framework. For instance, it may be beneficial to announce the path of government spending and taxes with some regularity and make this announcement reasonably visible for agents in the economy. This will be especially effective in a scenario of high deficit expectations, where an upward revision ("bad news") of deficit projections have the potential to increase future interest rates. In so far as high deficit and debt dampen the Fed's monetary policy effectiveness, this might be a prudent cmyse of action for fiscal policymakers. Finally, I believe that my empirical result can be used as a motivation for future theoretical work to develop 
realistic dynamic stochastic general equilibrium class models that account for the non-linearity between deficit and interest rate to better understand the forces driving differences in the impact of deficit expectations on future interest rates during different regimes, the exact dynamics and consequences of such impact and policy implications of managing expectations of deficit.

\section{References}

Auerbach, A. J., and Y. Gorodnichenko (2012 A): 'Measuring the Output Responses to Fiscal Policy', American Economic Journal: Economic Policy, American Economic Association, 4(2), $1-27$.

Auerbach, A. J., and Y. Gorodnichenko (2012 B). 'Fiscal Multipliers In Recession And Expansion', NBER Chapters, In: 'Fiscal Policy After The Financial Crisis', National Bureau Of Economic Research.

Barro, R. J. (1989). 'The Ricardian Approach To Budget Deficits', Journal of Economic Perspectives, 3 (2), 37-54.

Bernanke, B. S., and A. S. Blinder (1992). 'The Federal Funds Rate And The Channels Of Monetary Transmission', American Economic Review, 82 (4), 901-921.

Bernanke, B. S., and I. Mihov (1998). 'Measuring Monetary Policy', Quarterly Journal of Economics, 113 (3), 869-902.

Blanchard, O., And R. Perotti (2002). 'An Empirical Characterization Of The Dynamic Effects Of Changes In Government Spending And Taxes On Output', Quarterly Journal Of Economics, 117(4), 1329-68. 
Bernheim, B. D. (1987). 'Ricardian Equivalence: An Evaluation Of Theory And Evidence', NBER Working Paper 2330, July.

Bernheim, B. D. (1989). ‘A Neoclassical Perspective On Budget Deficits', Journal Of

Economic Perspectives, 3 (2), 55-72.

Candelon, B., And L. Lieb (2011). 'Fiscal Policy In Good And Bad Times', Research Memoranda 001, Maastricht: Meteor, Maastricht Research School Of Economics Of Technology And Organization.

Canzoneri, M. B., R. E. Cumby, And B. T. Diba (2002). 'Should The European Central Bank And The Federal Reserve Be Concerned About Fiscal Policy?' Paper Presented At The Federal Reserve Bank Of Kansas City’s Symposium On 'Rethinking Stabilization Policy', Jackson Hole, Wyoming, August.

Cohen, D., And O. Garnier (1991). 'The Impact Of Forecasts Of Budget Deficits On Interest Rates In The United States And Other G-7 Countries', Working Paper, Federal Reserve Board.

Dufmy, J. M. (1997). 'Some Impossibility Theorems In Econometrics With Applications To Structural Variables And Dynamic Models', Econometrica, 65, 1365-1387.

Elmendorf, D.W. (1993). 'Actual Budget Deficit Expectations And Interest Rates', Working Paper, Harvard Institute Of Economic Research.

Elmendorf, D.W. And N. G. Mankiw (1999). 'Government Debt', In Handbook Of Macroeconomics (1c), Elsevier Science B.V.

Engen, E. M. And R. G. Hubbard (2004). 'Federal Government Debt And Interest Rates', NBER Macroeconomic Annual.

Fatas, A., And I. Mihov (2000). 'Fiscal Policy And Business Cycles: An Empirical Investigation', Mimeo, INSEAD. 
Gale, W. G., And P. R. Orszag (2002). 'The Economic Effects Of Long-Term Fiscal Discipline', Working Paper, Tax Policy Center, Urban Institute And Brookings Institution.

Gale, W. G. And P. R. Orszag (2003). ‘Economic Effects Of Sustained Budget Deficits', National Tax Journal 56 (3), 463-85.

Gale, W. G. And P. R. Orszag (2004). 'Budget Deficits, National Saving, And Interest Rates', Working Paper, Tax Policy Center And Brookings Institution.

Gürkaynak, R., B. Sack, And J. Wright (2007). 'The U.S. Treasury Yield Curve: 1961 To The Present', Journal Of Monetary Economics, 54, 2291-2304.

Hansen, B. E. (1996). 'Inference When A Nuisance Parameter Is Not Identified Under The Null Hypothesis', Econometrica 64(2), 413-430.

Hansen, B.E. (1997). 'Inference In TAR Models', Studies In Nonlinear Dynamics And Econometrics 2(1), 1-14.

Hansen, B. E. (2000). 'Sample Splitting And Threshold Estimation', Econometrica, 68, 575603.

Mountford, A. And H.Uhlig (2000). 'What Are The Effects Of Fiscal Policy Shocks', Centre For Economic Policy Research.

Perotti, R. (2002). ‘Estimating The Effects Of Fiscal Policy In OECD Countries', Isom Conference, Frankfurt.

Laubach, T. (2009). 'New Evidence On The Interest Rate Effects Of Budget Deficits And Debt', Journal Of The European Economic Association, 7(4), 858-885.

Seater, J. J. (1993). 'Ricardian Equivalence', Journal Of Economic Literature, 31(1), 142-190. 
Tsay, R. S. (1998). 'Testing And Modeling Multivariate Threshold Models', Journal Of The American Statistical Association, 93, 1188-1202.

Wachtel, P., And J. Young (1987). 'Deficit Announcements And Interest Rates', American Economic Review, 77, 1007-1012.

Woodford, M. (2003). 'Interest And Prices: Foundations Of A Theory Of Monetary Policy', Princeton University Press. 


\section{TABLE 1}

Threshold estimation in regression using 5-year-ahead 5 year interest rate and 5-year-ahead 10-year interest rate as the dependent variable

\begin{tabular}{lll}
\hline Dependent Variable & $\begin{array}{l}\text { 5-year-ahead 5 year } \\
\text { interest rate }\end{array}$ & $\begin{array}{l}5 \text {-year-ahead } \\
\text { interest rate }\end{array}$ \\
\hline Threshold Estimate $d_{t}:$ & $\mathbf{1 . 8 0 0}$ & $\mathbf{1 . 8 0 0}$ \\
0.95 Confidence Interval: & {$[-0.319,2.691]$} & {$[-0.319,2.691]$} \\
Sum of Squared Errors: & 20.670 & 18.45 \\
Joint R-squared: & 0.885 & .887 \\
Heteroskedasticity Test (P-Value) & 0.657 & .704 \\
\hline Note: $\mathrm{d}_{\mathrm{t}}$ is projected deficit-GDP ratio. & & \\
\hline
\end{tabular}

TABLE 2

Regression of future interest rate on projected deficit and other regressors:

Full sample

\begin{tabular}{lll}
\hline Dependent Variable & $\begin{array}{l}\text { 5-year-ahead } \\
\text { 5 year interest rate }\end{array}$ & $\begin{array}{l}\text { 5-year-ahead } \\
10 \text { year interest rate }\end{array}$ \\
& Estimate & Estimate \\
\hline Variable & & \\
\hline & $3.226(0.869)$ & $3.339(0.888)$ \\
Constant & $1.619(0.124)$ & $1.521(0.116)$ \\
$\pi_{t}$ (projected inflation) & $-0.592(0.331)$ & $-0.456(0.331)$ \\
$y_{t}$ (projected GDP growth rate) & $\mathbf{0 . 1 6 3 ( 0 . 0 5 2 )}$ & $\mathbf{0 . 1 8 1}(\mathbf{0 . 0 5 1})$ \\
$d_{t}$ (projected deficit-GDP ratio) & 28.915 & 26.752 \\
Sum of Squared Errors: & 0.83 & 0.84 \\
R-squared: & 0.035 & 0.008 \\
Heteroskedasticity Test (P-Value) & & \\
\hline
\end{tabular}




\section{TABLE 3.1}

Regression of future interest rates on projected deficit and other regressors:

Split Sample (Regime 1)

\begin{tabular}{|c|c|c|}
\hline Regime 1: & $d_{t} \leq 1.8$ & \\
\hline Dependent Variable & $\begin{array}{l}5 \text {-year-ahead } \\
5 \text { year interest rate }\end{array}$ & $\begin{array}{lll}\text { 5-year-ahead } & 10 & \text { year } \\
\text { interest rate } & & \end{array}$ \\
\hline \multicolumn{3}{|l|}{ Parameter Estimates } \\
\hline Variable & Estimate & Estimate \\
\hline Constant & $3.56(0.89)$ & $3.39(0.81)$ \\
\hline$\pi_{t}$ (projected inflation) & $1.35(0.12)$ & $1.31(0.12)$ \\
\hline$y_{t}($ projected GDP growth rate $)$ & $-0.49(0.31)$ & $-0.32(0.31)$ \\
\hline$d_{t}$ (projected deficit-GDP ratio) & $-0.18(0.21)$ & $0.00(0.06)$ \\
\hline Observations: & 30 & 30 \\
\hline Sum of Squared Errors: & 11.37 & 11.09 \\
\hline Residual Variance & 0.45 & 0.43 \\
\hline R-squared: & 0.80 & 0.82 \\
\hline
\end{tabular}


TABLE 3.2

Regression of future interest rates on projected deficit and other regressors:

Split Sample (Regime 2)

\begin{tabular}{|c|c|c|}
\hline Regime 2: & $d_{t}>1.8$ & \\
\hline Dependent Variable & $\begin{array}{l}5 \text {-year-ahead } 5 \text { year } \\
\text { interest rate }\end{array}$ & $\begin{array}{lll}\text { 5-year-ahead } & 10 & \text { year } \\
\text { interest rate } & & \end{array}$ \\
\hline \multicolumn{3}{|l|}{ Parameter Estimates } \\
\hline Variable & Estimate & Estimate \\
\hline Constant & $3.05(0.92)$ & $3.15(0.90)$ \\
\hline$\pi_{t}$ (projected inflation) & $1.92(0.15)$ & $1.83(0.15)$ \\
\hline$y_{t}($ projected GDP growth rate $)$ & $-0.95(0.39)$ & $-0.81(0.40)$ \\
\hline$d_{t}$ (projected deficit-GDP ratio) & $0.30(0.13)$ & $0.29(0.14)$ \\
\hline Observations: & 25 & 25 \\
\hline Sum of Squared Errors: & 8.12 & 7.36 \\
\hline Residual Variance & 0.38 & 0.35 \\
\hline R-squared: & 0.90 & 0.91 \\
\hline
\end{tabular}

Note: Boot-strapped standard errors in parenthesis 
Figure 1.Interest Rates and Long Horizon Inflation Expectations

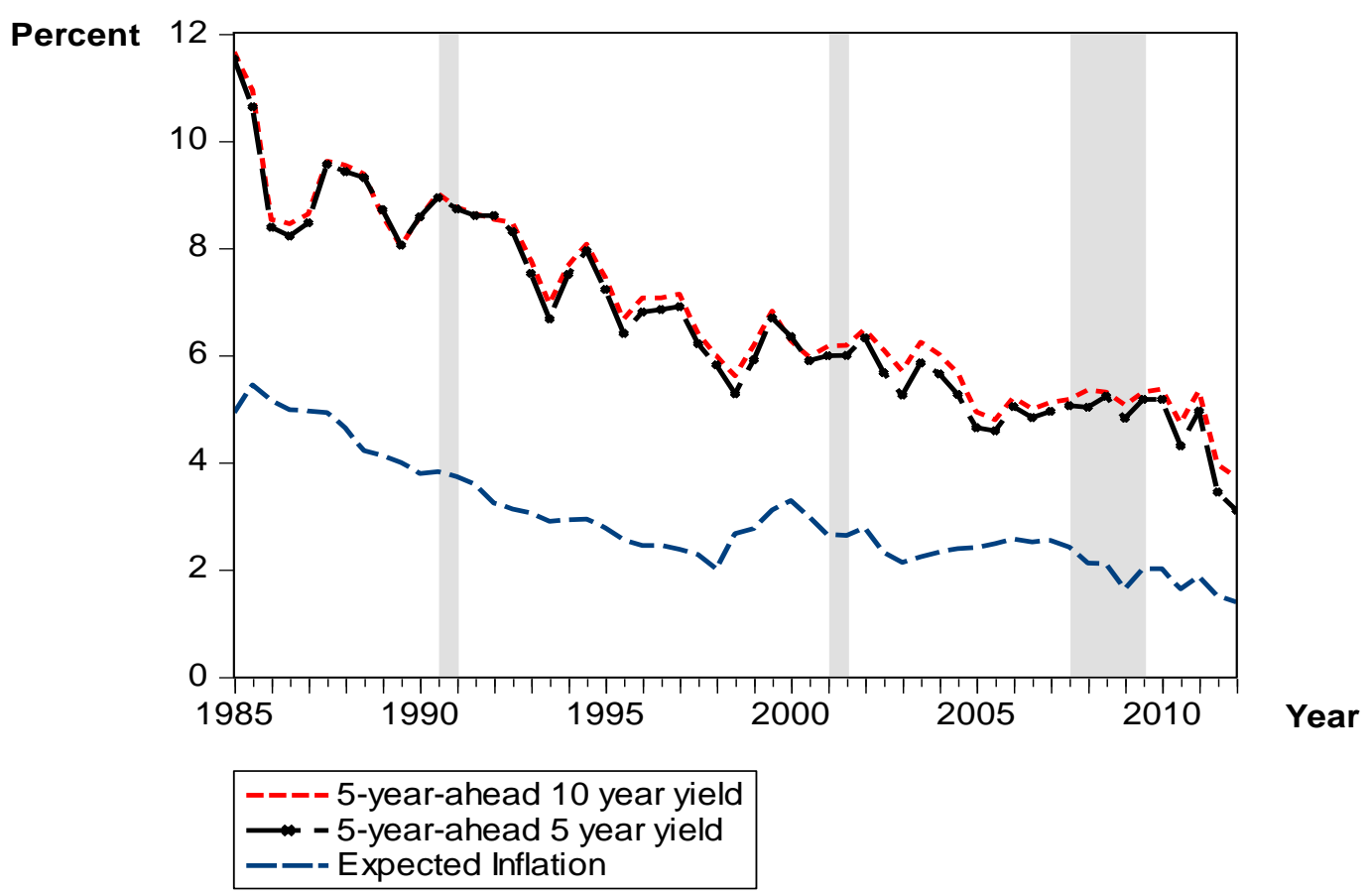


Figure 2.Projected Deficit and Projected GDP Growth Rates (year of projection)

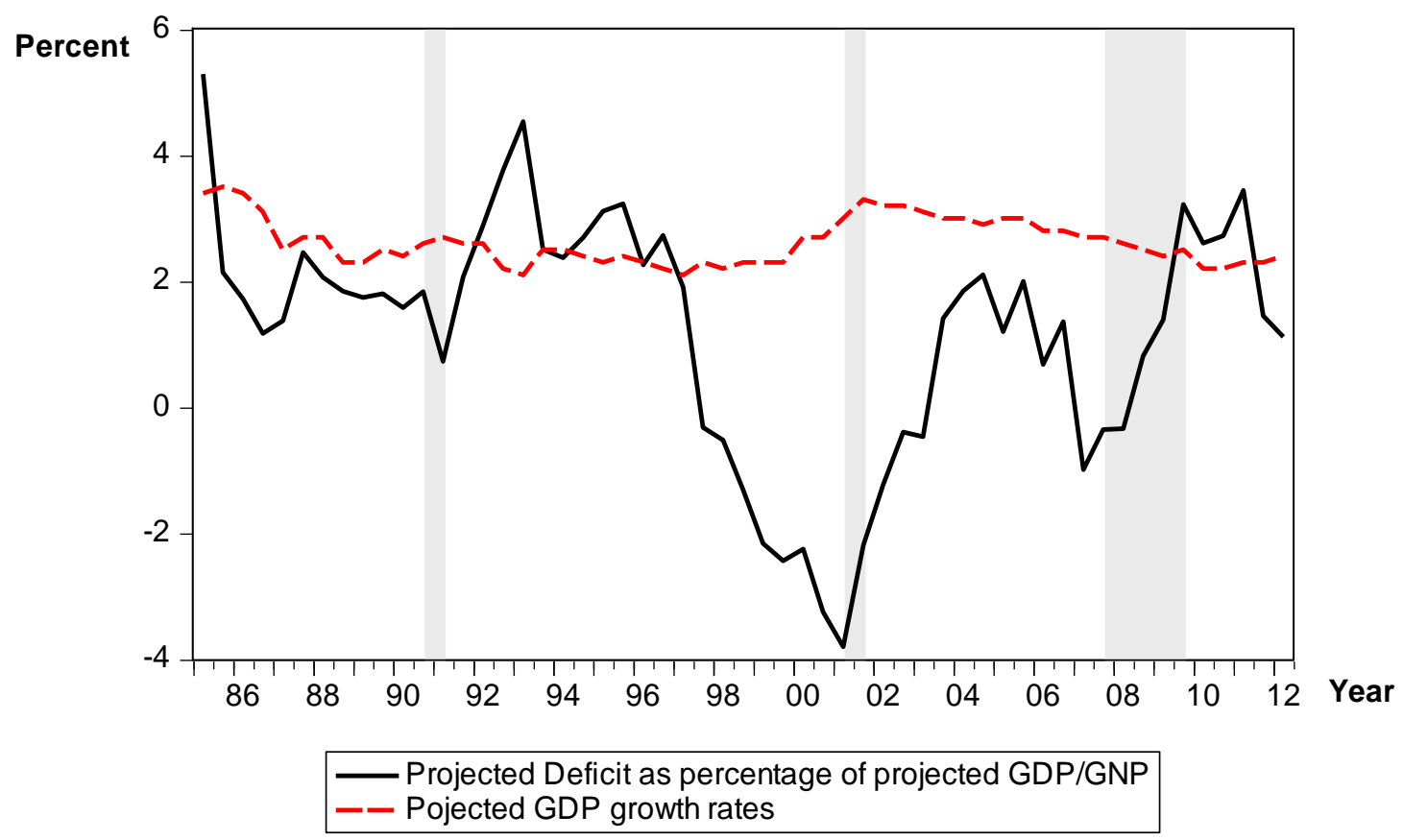


Figure 3. $90 \% \mathrm{~F}$ Test for presence of Threshold effect of expected deficit on 5-year-ahead 5 year interest rates

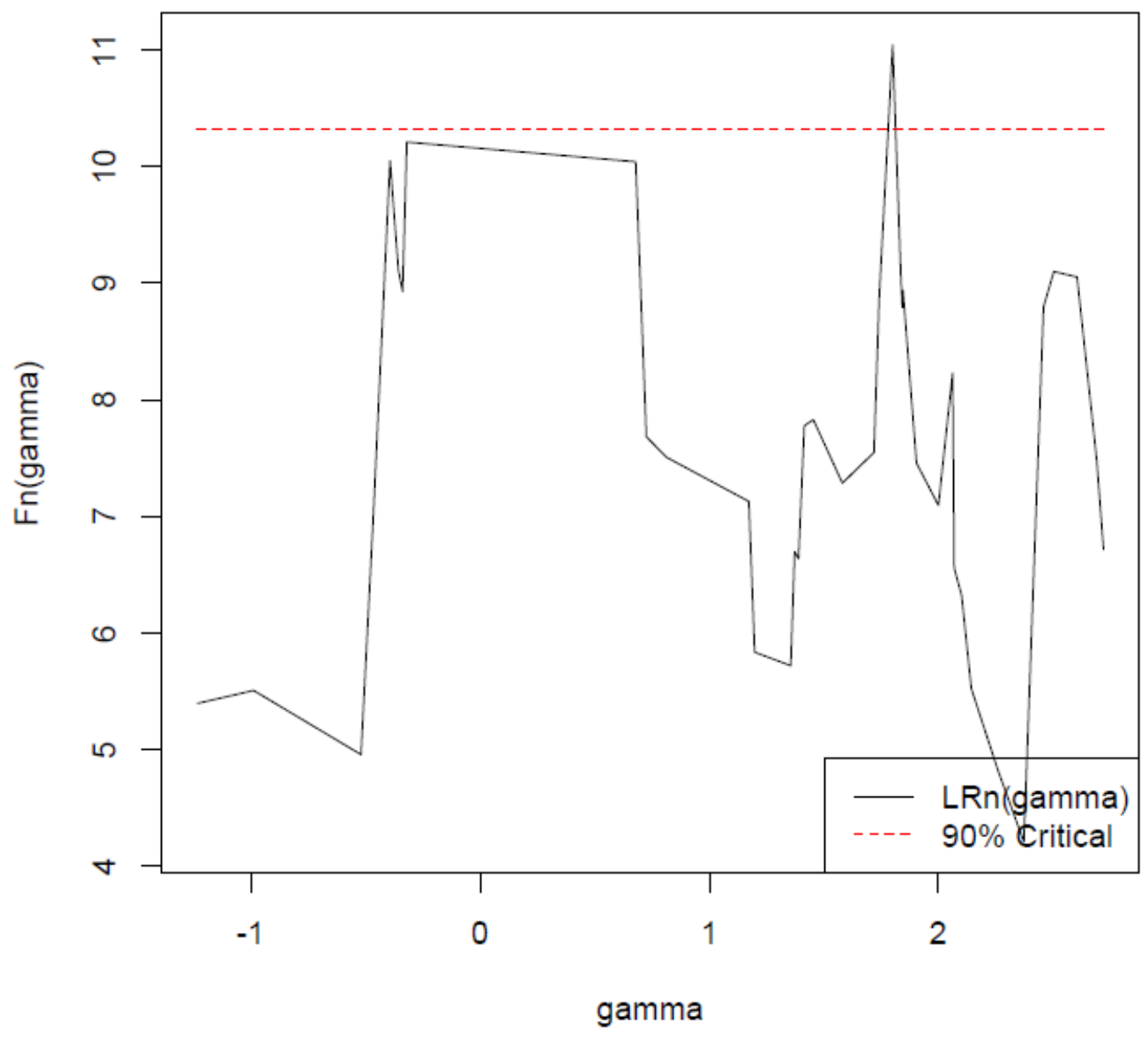

Note: Linearity is rejected if $\mathrm{F}$ sequence becomes greater than or equal to the $90 \%$ critical value. For 5year-ahead 5 year interest rates, the bootstrapped $\mathrm{P}$-value for $\mathrm{F}$ sequence greater than $95 \%$ critical is 0.052 ; hence the line just about touches the $95 \%$ critical, but crosses the $90 \%$ critical line. 
Figure 4. 95\% F Test for presence of Threshold effect of expected deficit on 5-year-ahead 10 year interest rates

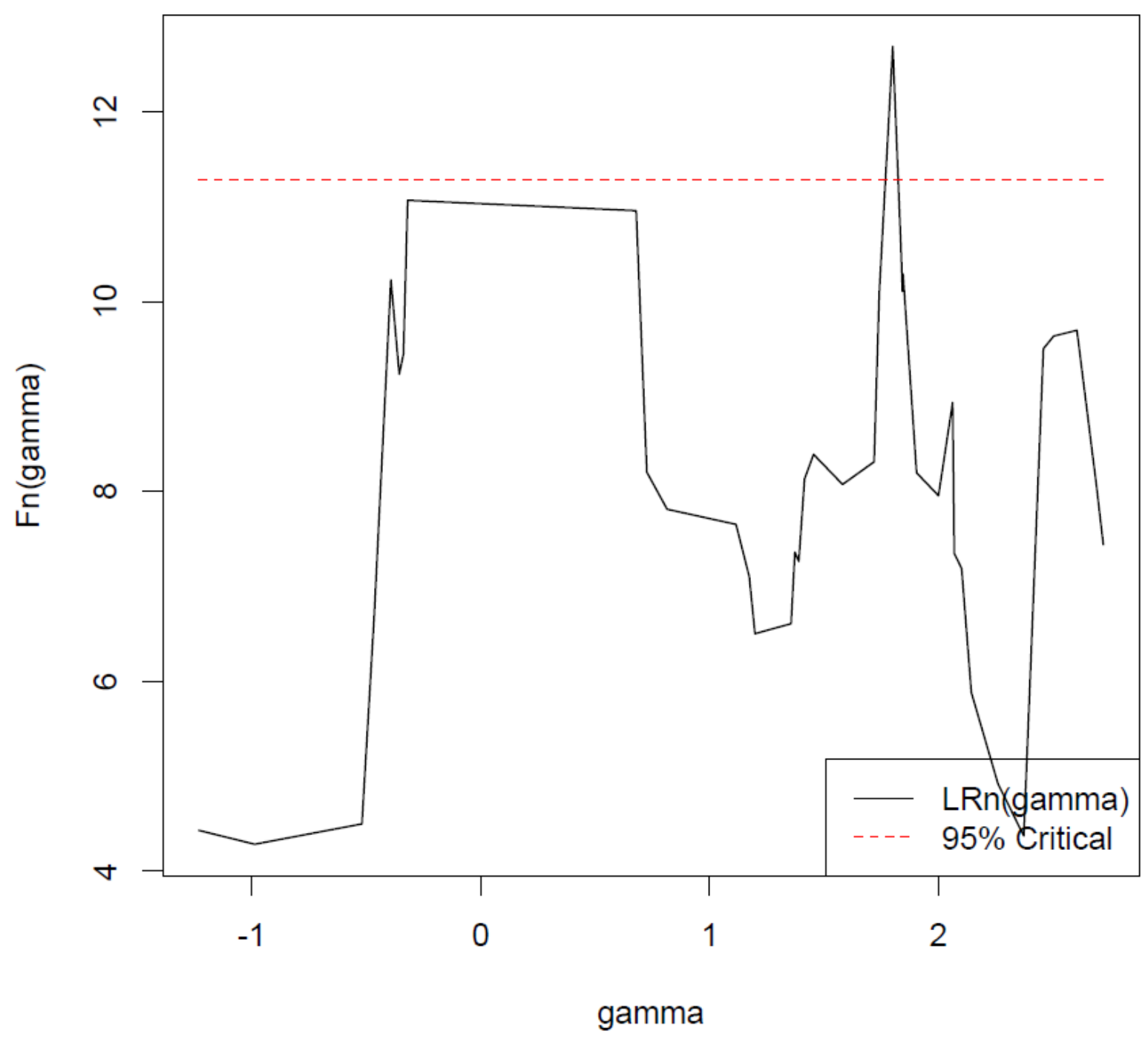

Note: Linearity is rejected if $\mathrm{F}$ sequence becomes greater than or equal to the $95 \%$ critical value. 
Figure 5.Confidence interval construction for threshold in Deficit/GDP ratio while regressing on 5-yearahead 5 year interest rate

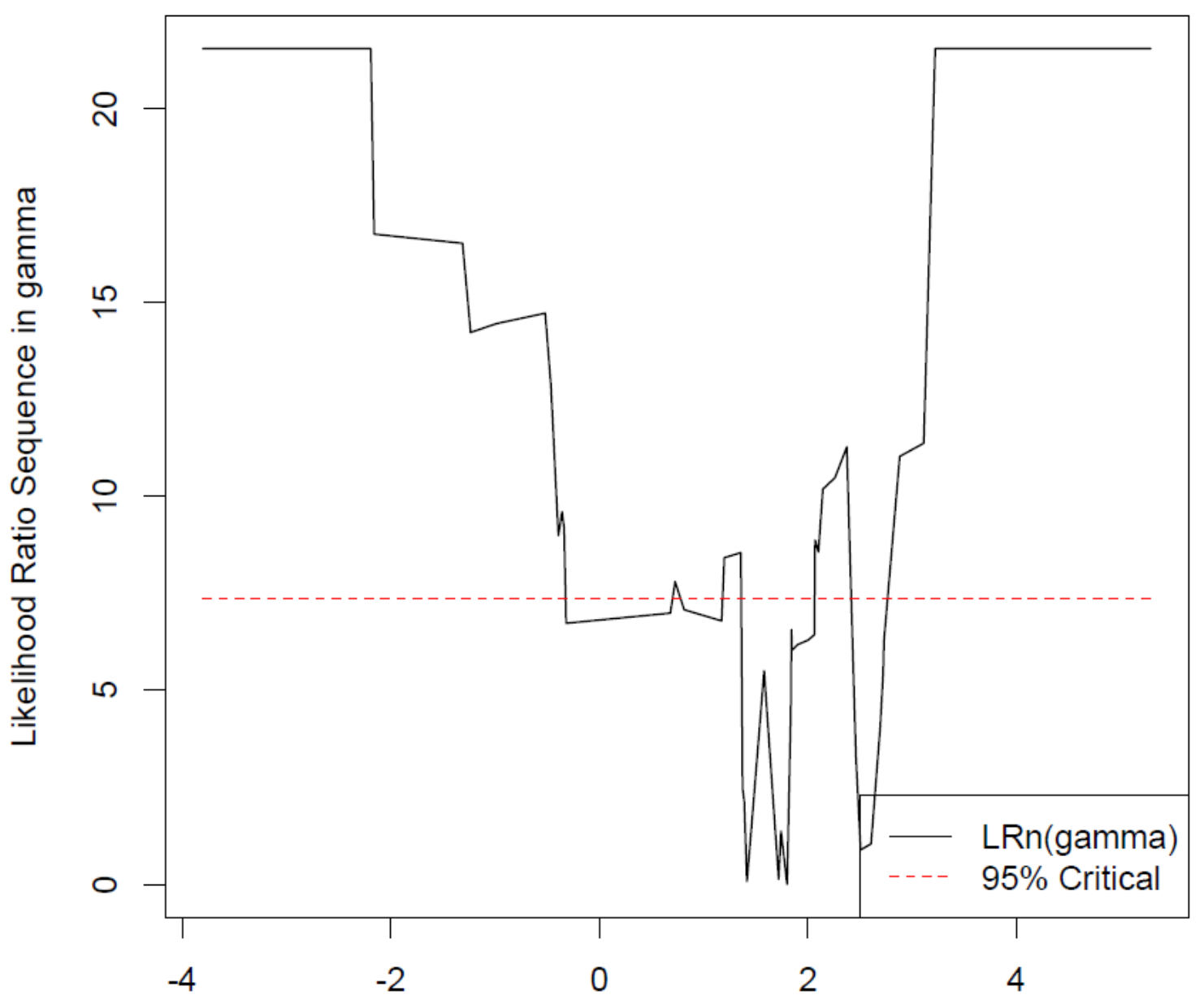


Figure 6.Confidence interval construction for threshold in Deficit/GDP ratio while regressing on 5-yearahead 10 year interest rate

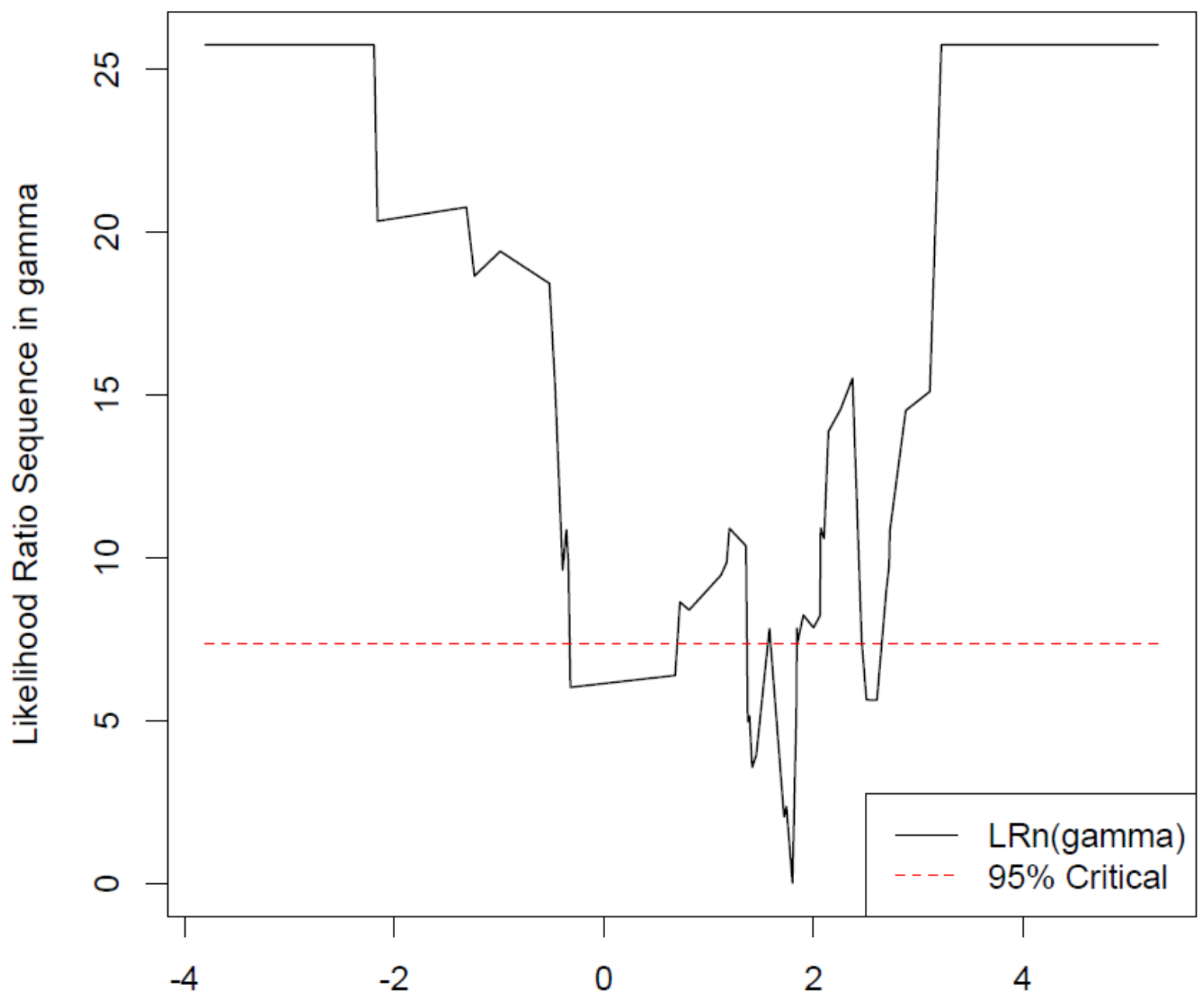


Figure 7.Response of 5-year-ahead 5 year Interest Rate to One S.D. Innovation to Projected Deficit-GDP ratio in Regime 1 ("regime of low expected deficit")

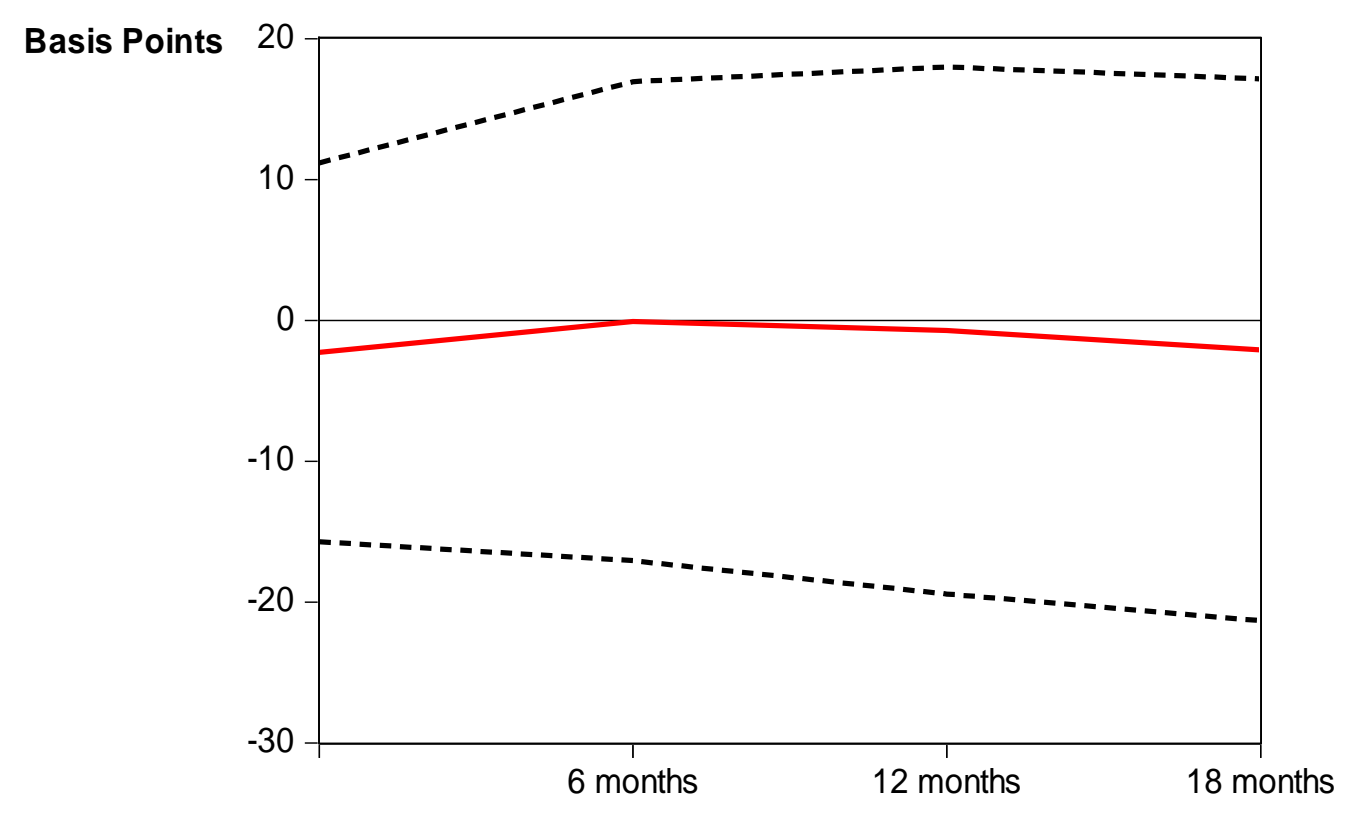


Figure 8.Response of 5-year-ahead 5 year Interest Rate to One S.D. Innovation to Projected Deficit-GDP ratio in Regime 2 ("regime of high expected deficit")

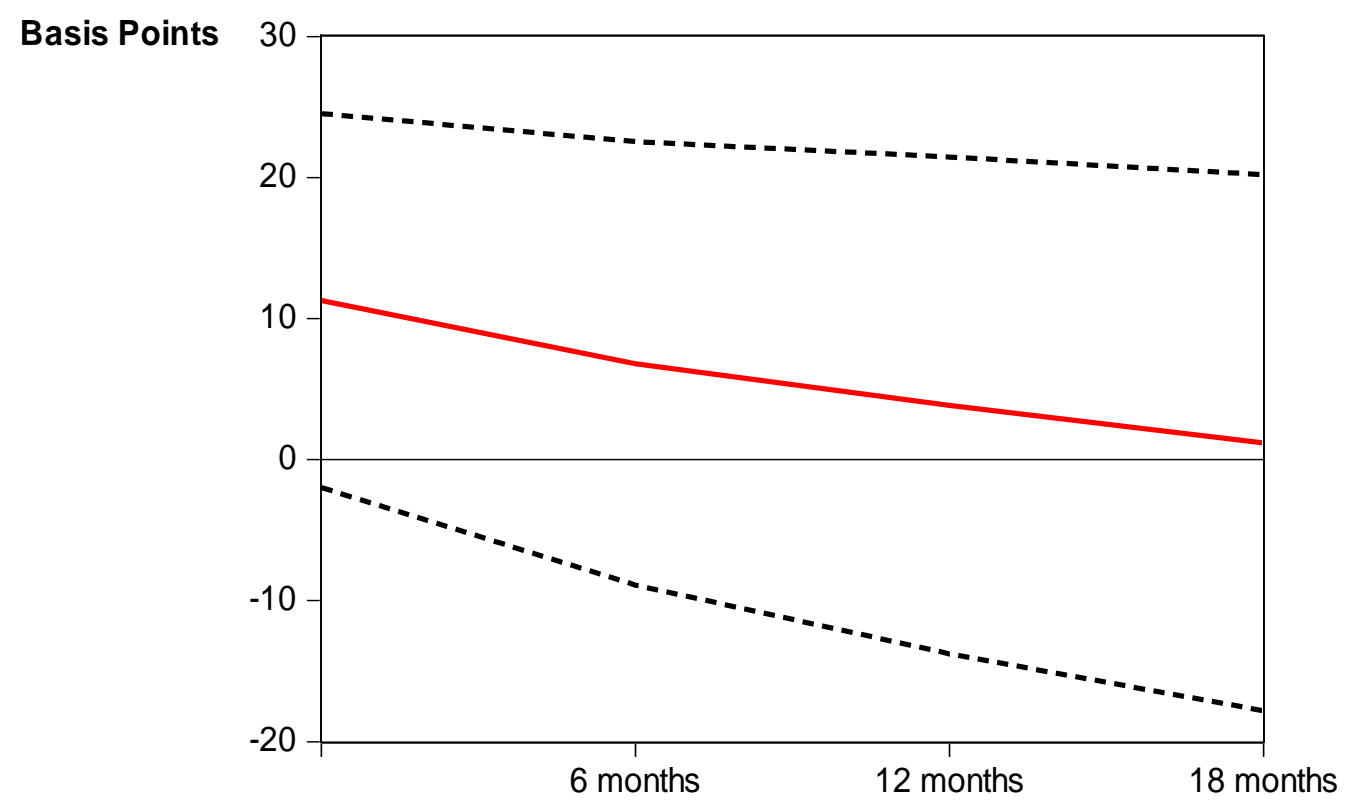


Figure 9.Response of 5-year-ahead 10 year Interest Rate to One S.D. Innovation to Projected Deficit-GDP ratio in Regime 1 ("regime of low expected deficit")

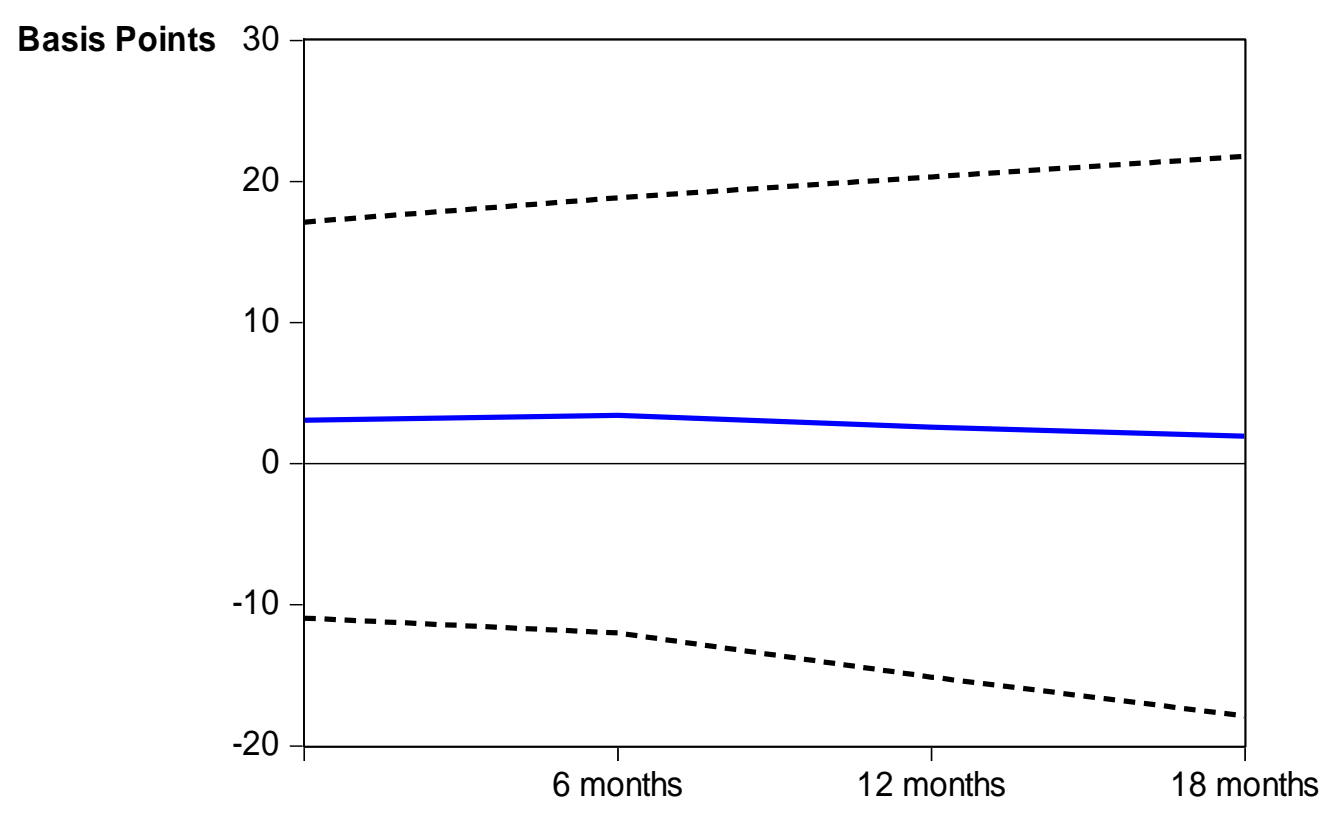


Figure 10.Response of 5-year-ahead 10 year Interest Rate to One S.D. Innovation to Projected DeficitGDP ratio in Regime 2 ("regime of high expected deficit")

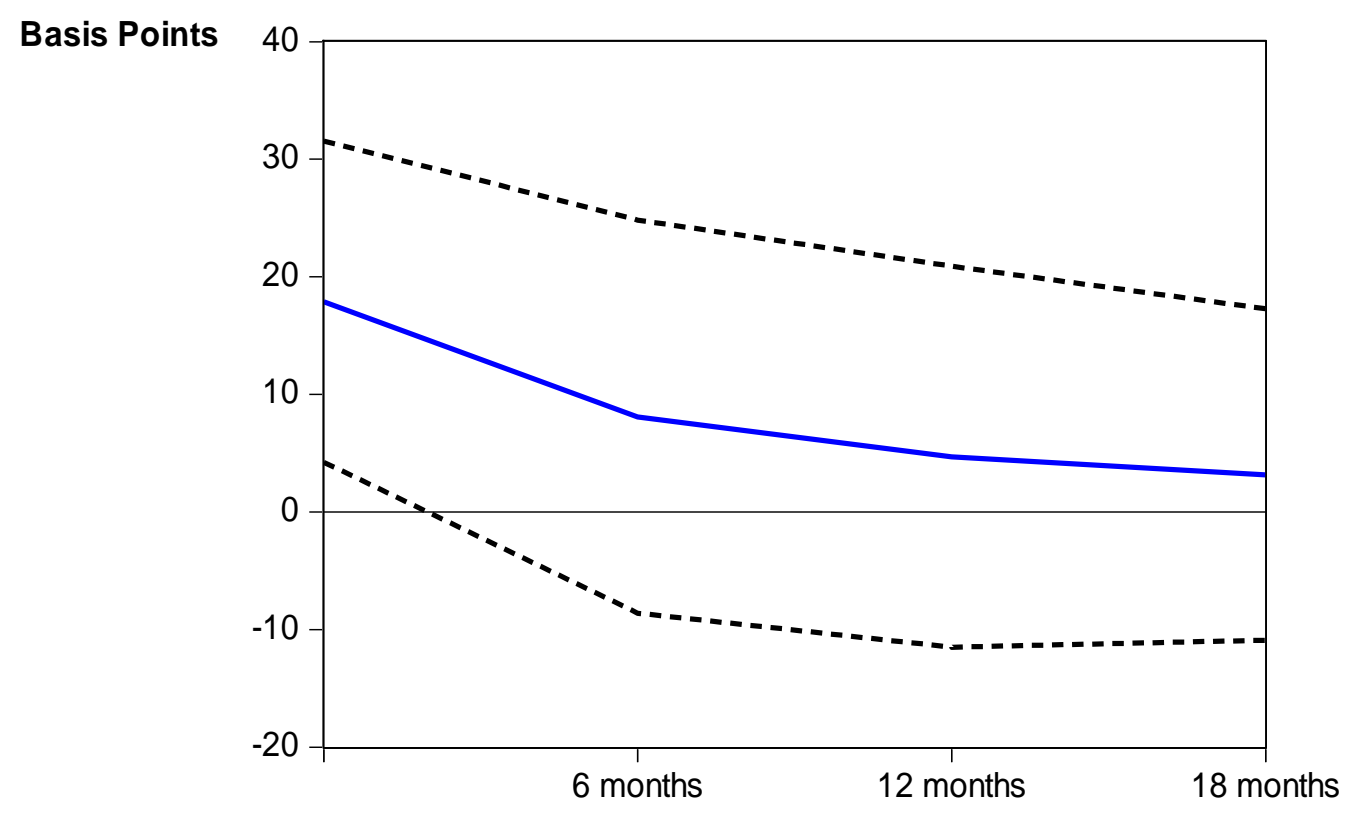


Figure 11.Summary Statistics of Projected Deficit/GDP Ratio

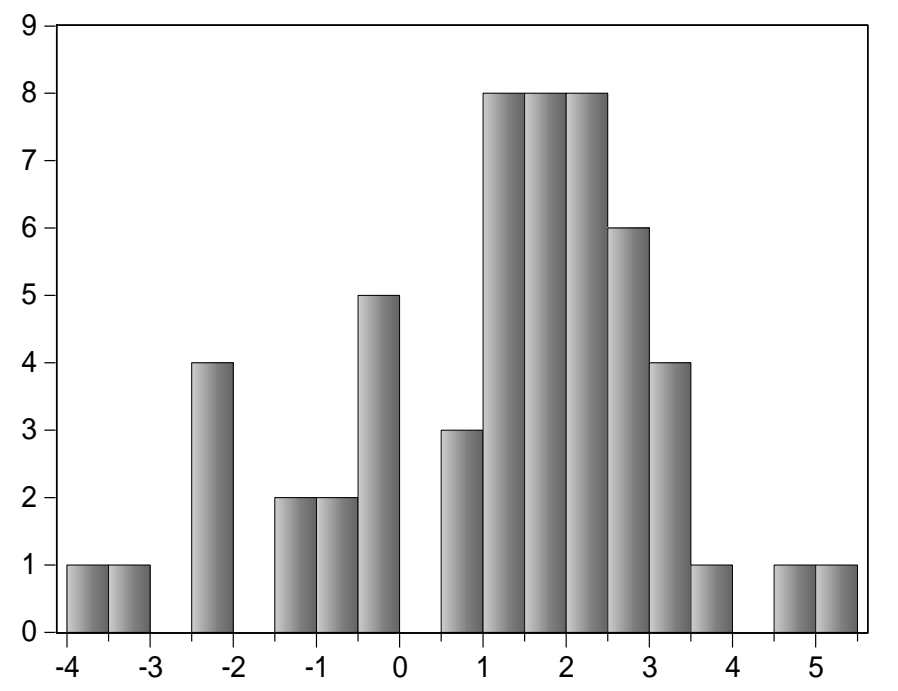

Series: Projected Deficit GDP Ratio Sample: 1985 - 2012

Frequency: Semi-annual

Mean $\quad 1.184733$

Median $\quad 1.719861$

Maximum $\quad 5.288041$

Minimum $\quad-3.802997$

Std. Dev. $\quad 1.931046$

Skewness $\quad-0.645207$

Kurtosis $\quad 3.086528$

Jarque-Bera $\quad 3.833164$

Probability $\quad 0.147109$ 
Figure 12.Descriptive Statistics of Projected GDP/GNP Growth Rates

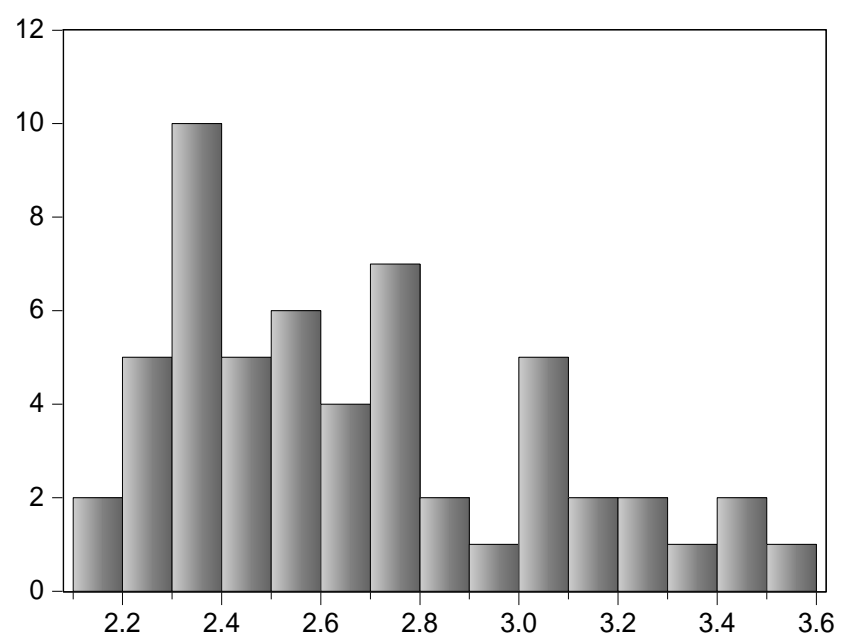

Series: Projected GDP/GNP Growth Rates Sample: $1985-2012$

Frequency: Semi-annual

Mean $\quad 2.621818$

Median $\quad 2.500000$

Maximum $\quad 3.500000$

Minimum 2.100000

Std. Dev. $\quad 0.367015$

Skewness $\quad 0.674924$

Kurtosis $\quad 2.500700$

Jarque-Bera 4.746935

Probability $\quad 0.093157$ 


\section{Appendix A}

Data Description:

Expected Inflation: the series is spliced using data from fmy smyces:

- January 1960 - September 1980: the inflation endpoint constructed by Kozicki and Tinsley (JME 2001);

- October 1980 - October 1991: linearly interpolated data from Hoey is used after subtracting 0.55 percentage point (annual rate) to transform the data from a CPI inflation basis to a PCE inflation basis;

- November 1991 - 2005: linearly interpolated SPF survey data is used after subtracting 0.55 percentage point (annual rate) to transform the data from a CPI inflation basis to a PCE inflation basis.

- November 2005- January 2012: Inflation expectations from Cleveland Fed using a new approach to gauging private sector inflation expectations of various horizons. See commentary of Haubrich, $\mathrm{J}$ at Cleveland Fed: http://www.clevelandfed.org/research/commentary/2009/0809.cfm

\section{5 year-ahead 5 year interest rate:}

Average of one-year forward rates 5-9 years ahead, calculated from the zero coupon yield curve, sampled on the last trading day of the month of the $\mathrm{CBO}$ release.

\section{5 year-ahead 10 year interest rate:}

Average of one-year forward rates 5-14 years ahead, calculated from the zero coupon yield curve, sampled on the last trading day of the month of the CBO release.

Equity Premium: Calculated as the dividend component of national income, expressed as percent of the market value of corporate equity held (directly or indirectly) by households Smyce: Flow of Funds account in FRED database. 
